\title{
Violência conjugal: as controvérsias no relato dos parceiros íntimos em inquéritos policiais
}

\author{
Conjugal violence: controversies in the reports \\ of intimate partners in police investigations
}

Anne Caroline Luz Grüdtner da Silva ${ }^{1}$

Elza Berger Salema Coelho ${ }^{1}$

Kathie Njaine ${ }^{2}$

\footnotetext{
${ }^{1}$ Departamento de Saúde Pública, Centro de Ciências da Saúde, Universidade Federal de Santa Catarina. Cidade Universitária, Trindade. 88.040-970 Florianopolis SC Brasil. anne_clg@hotmail.com ${ }^{2}$ Escola Nacional de Saúde Pública, Fundação Oswaldo Cruz.
}

Abstract This article analyzes the motivation behind domestic violence based on the testimonies of men and women registered in police investigations by the Sixth Police Station for Women, Children and Adolescents in Florianópolis in the state of Santa Catarina in 2010. It is the result of a quantitative and qualitative survey conducted between August and November 2011. The information obtained in the investigation into domestic violence perpetrated by partners or ex-partners and containing the testimony of the couple in 172 police investigations was analyzed. The issues selected for analysis were the profile of the couple and the reports of violence according to the women and the men. The results showed that most of the couples were separated or divorced, aged between 31 and 40, gainfully employed and had lived together between one and eleven years. The assaults occurred due to drug use and/or jealousy. The men blamed the women for being responsible for their acts or played down the situation and claimed to be victims of violence committed by the partners. The study concludes that cultural issues of gender and socio-economic characteristics are linked to this type of violence, and showed that men do not acknowledge their actions as being violent, most often downplaying the consequences of such violence.

Key words Domestic violence, Violence against women, Spousal abuse
Resumo Este artigo investiga as motivações da violência conjugal segundo os depoimentos de homens e mulheres registrados nos inquéritos policiais (IP) da $6^{a}$ Delegacia de Polícia de Proteção à Mulher, à Criança e Adolescente de Florianópolis, Santa Catarina, em 2010. Pesquisa quantiqualitativa realizada entre agosto e novembro de 2011. Foram analisadas as informações obtidas nos inquéritos sobre violência doméstica perpetrada pelo companheiro ou ex-companheiro e que continham o depoimento do casal, totalizando 172 IP. Os aspectos selecionados para a análise referem-se ao perfil do casal, e aos relatos da violência segundo a mulher e o homem. Os resultados apontaram que a maioria dos casais eram separados ou divorciados, com idade entre 31 e 40 anos, estavam empregados e conviveram entre um e onze anos. As agressões ocorreram em função do uso de drogas e ciume, os homens ao assumirem a violência exercida culpam a mulher de serem responsáveis por seus atos ou minimizam a situação, e acrescentam serem vítimas de violência cometida pela companheira. O estudo conclui que questões culturais de gênero e socioecônomicas estão relacionadas a este tipo de violência, e demonstrou que os homens não reconhecem suas atitudes como violentas, banalizando na maioria das vezes as consequências dessa violência.

Palavras-chave Violência Doméstica, Violência contra a mulher, Maus-tratos conjugais 


\section{Introdução}

A violência contra a mulher é reconhecida como um fenômeno social e da saúde pública, encontrada em diferentes tipos de cultura e classes sociais, se apresentando sob várias formas, dentre elas a que ocorre entre parceiros íntimos dentro ou fora do ambiente doméstico, conhecida como violência doméstica. Esta se define como qualquer comportamento dentro de um relacionamento íntimo que cause dano físico, moral ou sexual ao companheiro. É praticada pelo parceiro ou cônjuge dentro de um relacionamento íntimo, e também pelo ex-parceiro quando a relação termina ${ }^{1,2}$.

A maneira de ampliar o foco da discussão da violência contra a mulher passa pela compreensão de tal temática como uma forma de violência de gênero. Este diz respeito às relações de poder e à distinção entre as características culturais atribuídas a cada um dos sexos e suas peculiaridades biológicas. O uso do poder do homem sobre as mulheres estaria então na base da violência exercida contra elas, e seria uma forma de dominá-las e controlá-las, principalmente se a vítima for sua parceira numa relação conjugal ${ }^{1,3}$.

Este tipo de violência traz graves consequencias à saúde da mulher, como o aumento das taxas de suicídio, do uso de drogas e álcool, e outros agravos; como cefaleias, traumatismos, problemas gastrointestinais, ginecológicos, doenças sexualmente transmissíveis, gravidez indesejada, aborto espontâneo, distúrbios alimentares, depressão e ansiedade ${ }^{4,5}$. Segundo o Banco Interamericano de Desenvolvimento (BID) ${ }^{6}$, a violência conjugal contra a mulher também se reflete na perda de produtividade, diminuição do desempenho no trabalho, absenteísmo laboral e perda do emprego. Além dos custos humanos, este tipo de violência resulta em uma imensa carga econômica para as sociedades e um aumento na necessidade de serviços sociais ${ }^{2}$.

A proporção de mulheres que sofreram violência física durante algum momento da vida varia de $12 \%$ na China, $48 \%$ na Austrália e Moçambique, até 59\% na Zâmbia. Quando avaliada a violência praticada pelo parceiro íntimo a variação foi de $6 \%$, na China, até $48 \%$ na Zâmbia e no Peru ${ }^{7}$.

No Brasil, entre as mulheres que relataram ter sofrido algum tipo de violência, $46 \%$ informaram agressão física, 33\% ameaça e 15\% violência sexual. Dos homens entrevistados, 15\% relataram ter cometido agressão grave contra a mulher, destes $34 \%$ agrediram fisicamente, $9 \%$ ameaçou e $2 \%$ obrigou a mulher a manter relação sexual ${ }^{8}$.

Historicamente, na América Latina os estudos privilegiaram a mulher enquanto vítima de violência praticada pelo parceiro íntimo, não incluindo os aspectos referentes ao agressor. Atualmente, no entanto, entende-se que o conhecimento maior sobre os autores da violência, podem oferecer subsídios para as políticas de enfrentamento à violência conjugal ou violência doméstica $^{9,10}$.

Frente às características dos estudos sobre violência contra a mulher, há necessidade de pesquisas que associem métodos quantitativos e qualitativos, e que detalhem o vínculo da mulher com o agressor. $\mathrm{O}$ aprofundamento do conhecimento do tema, a observação das características da agressão como percebidas por ambos e dos fatores que repercutem na ocorrência de violência doméstica podem contribuir para a construção de políticas fundamentadas para a mudança social e a diminuição do problema ${ }^{11,12}$.

A Delegacia da Mulher é considerada uma porta de entrada para os relatos de violência doméstica, podendo contribuir para uma nova etapa nas relações conjugais de quem procura este serviço. As informações contidas nos inquéritos policiais e processos penais, gerados após denúncias de violência entre casais, são dados oficiais desta realidade, que podem não representa-lo no todo, mas fornecem questões valiosas sobre um fenômeno que ainda é silenciado ${ }^{13,14}$.

Assim, este artigo busca analisar as motivações da violência nas relações de intimidade a partir do depoimento dos envolvidos; incluindo, desta forma, a ótica do homem acusado de perpetrar violência.

\section{Metodologia}

Este estudo caracteriza-se como descritivo-exploratório, com abordagem quanti-qualitativa, e foi desenvolvido com base nos inquéritos policiais registrados no ano de 2010, na 6a Delegacia de Polícia de Proteção à Mulher, à Criança e Adolescente de Florianópolis, Santa Catarina. Esta delegacia foi escolhida por atender aos casos de violência contra a mulher da Grande Florianópolis e por ser uma das primeiras delegacias especializadas neste tipo de atendimento no país, inaugurada em 1985.

Foram registrados 3310 boletins de ocorrência (BO) no ano do estudo, sendo instaurados 986 inquéritos policias (IP), destes, 553 eram re- 
ferentes à violência contra a mulher. A seleção inicial dos inquéritos foi realizada a partir da leitura do fato comunicado, que deveria conter violência doméstica perpetrada pelo companheiro ou ex-companheiro. Para a análise foram selecionados os inquéritos em que o homem acusado de perpetrar violência compareceu à delegacia para prestar depoimento, num total de 172 IPs; sendo que 30 homens solicitaram o direito de falar apenas em juízo no momento do depoimento. Foram excluídos os inquéritos encerrados a pedido da mulher (51) ou que não foram finalizados (330).

Os depoimentos selecionados foram transcritos do inquérito policial para um banco de dados montado no programa Excel. Para manter o anonimato, cada casal recebeu um número, de acordo com a entrada na planilha de dados, sendo o homem identificado como Sr.1 e a mulher Sra.1, e assim sucessivamente. Adotou-se a perspectiva de análise temática, proposta por Bardin $^{15}$ e sintetizada por Minayo ${ }^{16}$. Foi realizada a leitura flutuante dos depoimentos, seguida de uma leitura aprofundada, da ordenação dos dados, a classificação e a análise final. A partir da leitura e releitura dos depoimentos elegeram-se as categorias e subcategorias do estudo, conforme Quadro 1.

O perfil sociodemográfico dos casais foi obtido diretamente dos IPs, a partir de informações prestadas pelo próprio casal, e incluiu as seguintes variáveis: idade, escolaridade, estado civil, ocupação e tempo de relacionamento. Estes dados foram inseridos no programa Epidata e analisados com o programa Stata 9.

O presente estudo foi aprovado pelo Comitê de Ética em Pesquisa em Seres Humanos (CEP$\mathrm{SH}$ ) da Universidade Federal de Santa Catarina, atendendo à Resolução 196/96 ${ }^{17}$ do Conselho Nacional de Saúde, sendo o Termo de Consentimento Livre e Esclarecido dispensado.

\section{Resultados e discussão}

\section{O perfil dos casais}

Dos casais analisados neste estudo, 58,72\% estavam separados e mais de $55 \%$ conviveram entre 1 e 11 anos (30,80\% entre 1 e 6 anos, e $25 \%$ entre 6 e 11 anos). Dos homens, 36,04\% estavam na faixa entre 31 e 40 anos de idade (média 40,10 anos, DP 11,79); 40,7\% estudaram de 9 a 12 anos; e $92,44 \%$ estavam empregados. Das mulheres que registraram violência, $34,30 \%$ tinham entre 31 e
Quadro 1. Categorias de Análise dos Depoimentos.

\begin{tabular}{|l|l|}
\hline \multicolumn{1}{|c|}{ Categorias } & \multicolumn{1}{c|}{ Subcategorias } \\
\hline $\begin{array}{l}\text { Motivo da agressão } \\
\text { para as mulheres }\end{array}$ & $\begin{array}{l}\text { Uso de drogas pelo companheiro } \\
\text { Parceiro não aceitar o fim da relação } \\
\text { Ciúme }\end{array}$ \\
\hline $\begin{array}{l}\text { Motivo da agressão } \\
\text { para os homens }\end{array}$ & $\begin{array}{l}\text { Ciúme } \\
\text { Uso de álcool }\end{array}$ \\
\hline $\begin{array}{l}\text { Posição do homem } \\
\text { frente a violência }\end{array}$ & $\begin{array}{l}\text { Confirmação da violência } \\
\text { - culpabilização da mulher } \\
\text { - minimização da violência } \\
\text { Negação da violência } \\
\text { - desqualificação da mulher } \\
\text { - vitimização do homem } \\
\text { - tentativa de prejudicar o homem }\end{array}$ \\
\hline
\end{tabular}

40 anos de idade (média 36,17 anos, DP 10,75); $33,13 \%$ estudaram de 9 a 12 anos; $97,10 \%$ estavam empregadas.

Mesmo se tratando de uma amostra de conveniência, o que impede a generalização dos achados, a maioria dos dados pesquisados corrobora o encontrado na literatura sobre o tema. O estado civil separado ou divorciado predominou no grupo estudado, dado encontrado em outros estudos sobre o tema ${ }^{14,18,19}$. De acordo com Gupta et al. ${ }^{19}$, homens separados, divorciados e viúvos reportaram mais violência contra a companheira em relação aos homens casados.

Homem com idade entre 31 e 40 anos, e com baixa escolaridade estaria associado a maior risco de violência contra a companheira ${ }^{11,19,20,21}$. De acordo com Audi et al. ${ }^{22}$, até 8 anos de escolaridade aumenta em 1,5 vezes a chance de violência psicológica e quase dobra a chance de violência física e sexual; mesma situação encontrada nesta pesquisa onde $43,01 \%$ dos homens estudaram 8 anos ou menos.

Pesquisas mostram associação entre a situação de trabalho e violência, pois o fato do homem estar desempregado aumenta a probabilidade de ocorrer violência, enquanto ser assalariado está relacionado a menor risco de violência contra a parceira ${ }^{23,24}$. Contudo, neste estudo apenas $0,58 \%$ dos homens estavam desempregados, achado que corrabora com o encontrado por Moura et al..$^{20}$, onde $77 \%$ dos homens acusados de perpetrar violência contra a parceira estavam empregados. 
O perfil das mulheres analisadas neste estudo vão ao encontro da literatura sobre o tema, onde as mulheres que procuram atendimento nas delegacias tem entre 19 e 34 anos de idade, são amasiadas, baixo nível de qualificação profissional e remuneração $0^{11,18,25}$. Por outro lado, estes estudos mostram que essas mulheres têm baixa escolaridade, o que não apareceu nesta pesquisa.

Relacionamentos que duraram entre 1 e 6 anos incompletos $(29,07 \%)$ foram os mais frequentes, seguido de 6 a 11 anos (25\%), mostrando que muitas vezes a relação conflituosa é mantida. Outros estudos sobre o tema encontraram maior risco de violência contra a companheira em relacionamentos de até 5 anos, ou ainda que todas as variáveis estudadas tinham associação com a violência perpetrada pelo parceiro, exceto o tempo de relacionamento ${ }^{22,26}$.

\section{Motivo da Agressão para as mulheres}

O abuso de álcool e de outras drogas, como cocaína e crack, aparecem em grande parte dos depoimentos como o motivo ou desencadeador da violência: ele fica muito transtornado quando ingere bebida alcoólica (Sra. 38); é usuário de crack e cocaína e quando não pode usar o entorpecente desconta na declarante (Sra. 57); quando alcoolizado ficar agressivo e violento (Sra. 100).

O consumo de álcool pelo homem como um fator de risco para violência é consenso entre os estudos, que defendem que o álcool reduz as inibições e leva a um julgamento pobre, facilitando a perpetração de violência ${ }^{27-29}$. De acordo com Deeke et al. ${ }^{11}$ cerca de 30\% dos agressores estavam alcoolizados no momento da agressão, eles também concluíram que a violência entre casais muitas vezes é desencadeada pelo homem ao não aceitar que a parceira interfira em seus hábitos e comportamentos em relação ao uso do álcool.

A associação entre o uso de outras drogas e uma maior chance de cometer violência contra a companheira também é relatado por outros estudos sobre o tema, porém, em geral, as pesquisas sobre o uso de drogas ilícitas são limitadas, uma vez que os sujeitos podem omitir informações sobre seu uso, com medo de sofrer penalidades $^{20,22,30,31}$.

Em alguns casos a violência começa após o fim do relacionamento: com o rompimento o indiciado passou a ser violento (Sra. 92); ele não aceita o fim do relacionamento e ameaça de morte (Sra. 54). Lamoglia e Minayo ${ }^{14}$ observaram que em algumas situações a mulher começa a sofrer violência após a separação ao não querer a re- conciliação ou por iniciar outro relacionamento.

O ciúme também é percebido no relato das mulheres, como observado nos seguintes depoimentos: que ele agride, pois é extremamente ciumento (Sra. 62); o casal enfrentou várias discussões devido ao ciúme doentio dele (Sra. 74). No estudo conduzido por Deeke et al. ${ }^{11}$, o ciúme foi identificado como desencadeador dos episódios violentos por $50 \%$ das mulheres e por $23 \%$ dos homens, sendo que os homens relataram ter ciúmes da companheira em relação a amigas e exnamorados.

É possível que as agressões motivadas pelo ciúme tenham base nas concepções machistas, presentes em algumas culturas que acreditam que a mulher é posse do homem e por isso deve estar submissa a este ${ }^{14}$.

\section{Motivo da Agressão para os homens}

O ciúme, evidenciado pelas suspeitas de traição e comportamento controlador, é relatado pelos homens como o motivo da agressão. Os relatos a seguir exemplificam a afirmação: veio a saber que sua companheira mantinha um caso extraconjugal (Sr. 27); afirma que as proferiu [ameaças] em razão de ter descoberto que um ex-namorado desta havia combinado de se encontrar com ela (Sr. 21).

Ciúme e sentimento de traição se tornam fortes elementos desencadeadores da agressão contra a companheira, e movem o medo que o homem sente de perder o controle sobre a parcei$\mathrm{ra}^{11,32}$. Para Couto et $\mathrm{al}^{33}$ o ciúme entre os homens esteve relacionado a traição, e este constituiu um dos mais importantes pontos de convergência acerca da tolerância da violência contra a mulher. Os homens reconheceram que, de todas as situações de desentendimentos que possam ocorrer entre o casal, o ciúme e a suspeita de traição são as que mais lhes descontrolam. Estes sentimentos ferem diretamente a crença da virilidade e masculinidade, associada à violência como resposta.

A violência contra a parceira está associada ao modo que os homens são socializados, onde os meninos são ensinados a reprimir as emoções e a raiva é um dos poucos sentimentos que a sociedade aceita que eles demonstrem. Além disso, este tipo de violência se fundamenta nos papeis sexuais, onde a violência é justificável pelos homens quando as mulheres mantêm relações extraconjugais ou não cumprem o que é considerado que sejam suas responsabilidades domésticas $^{34}$. 
O uso de álcool também é relatado como o responsável pelo comportamento agressivo, sendo usado para explicar e desculpar sua conduta agressiva frente aos efeitos que o álcool pro$\mathrm{duz}^{32,35}$. Estes relatos exemplificam esta forma de minimizar o fato: alega que na data dos fatos estava alcoolizado (Sr. 33); confirma que estava embriagado (Sr. 38); que naquela data ingeriu 4 ou 5 copos de cerveja (Sr. 66). Embora alguns homens relacionem o uso de bebidas alcoólicas com os atos violentos, o uso de outras drogas não esteve presente em seus depoimentos, provavelmente devido ao local em que estes relatos foi obtido, uma delegacia, o que pode levar ao receio de sofrer alguma penalidade, esta limitação também foi observada por Dossi et al. ${ }^{30}$.

\section{Posição do homem frente à violência}

Entre os homens que admitem ter agredido a parceira, é possível perceber, um discurso que busca responsabilizar as mulheres pelas agressões sofridas. Observou-se neste discurso uma alternância de papeis, mesclando o de agressor e o de vítima. Ao responsabilizarem as mulheres pelas agressões a elas dirigidas, na maioria dos casos, os homens tentam desqualificar os depoimentos das mesmas, minimizar a violência e diminuir suas possíveis penalizações. Entretanto, em alguns casos, acabam por evidenciar a bidirecionalidade da violência no conflito conjugal ${ }^{13,35}$.

A agressão é então reconhecida como uma resposta à ação da companheira, ou seja, é culpa dela, como evidenciam os depoimentos: admite que agrediu fisicamente sua companheira, depois de ter sido agredido com palavras (Sr. 19); para se defender deu uma mordida na mão da vítima (Sr. 48); a companheira agrediu o interrogado que se defendeu a empurrando (Sr. 134).

Ao analisar a declaração de homens participantes de um programa de atenção à violência familiar, Rosa et al. ${ }^{35}$ identificaram a mulher como uma das responsáveis pela agressão. De acordo com estes homens, a presença de atitudes inadequadas da companheira, domínio da mulher sobre o companheiro e resposta à agressão física, verbal ou psicológica da companheira eram os motivadores da violência.

Em alguns relatos eles tentam mostrar que até tentaram resolver a situação, mas a forma que a mulher agiu levou a violência, achado confirmado no estudo de Lamoglia e Minayo ${ }^{14}$ e exemplificado por este depoimento: a companheira lhe respondeu com ironia e restou por agredi-la (Sr. 37).
As declarações trazem conotação de justificativa e naturalidade, como se fosse a única atitude possível de ser tomada, explicada como um ato de legítima defesa e minimizada, houve apenas um empurrão não espancamento ${ }^{13}$.

Estas explicações e minimização dos fatos estiveram presente neste estudo, conforme relatos a seguir: fez este gesto não pensando em machucala (Sr. 6); afirma que apenas a empurrou, sem causar lesões (Sr. 20); que foram só da boca para fora (Sr. 28); sem intenção acabou por feri-la no braço (Sr. 40); afirma que tentou beijar a vitima a força, mas não teve agressão (Sr. 53); em legítima defesa a lesionou na tentativa de segurá-la (Sr. 77); apenas a segurou pelo cabelo três vezes (Sr. 44). Consideram a violência tolerável ou compreensível, pois seria resultado da exacerbação de impulsos que são naturais aos homens ${ }^{33}$.

Para diminuir ou apagar a ação agressiva em seus relatos, os homens recorrem à indeterminação em frases onde os processos verbais constroem as cenas de violência, ou seja, os homens colocam-se como narradores de uma situação vivenciada por outros, ou ainda legitimam a ação diante da emoção causada pela atitude da mulher. ${ }^{13,35}$. Desta forma mostra o fato sem sujeito ou como algo fora do controle: afirma que na data houve uma discussão (Sr. 57); iniciou-se uma desavença generalizada (Sr. 32); relata como motivo para tal comportamento, um momento de fúria e descontrole (Sr. 27); afirma que no calor da emoção (Sr. 139); se encontrava com a cabeça quente (Sr. 108).

De acordo com Freitas ${ }^{13}$, além da negação explícita da agressão, o homem usa uma forma de negação dissimulada pelo esquecimento. Essa forma de negação esteve presente nos depoimentos analisados neste estudo quando relatam: que não se recorda se proferiu ameaças (Sr. 33); que não lembra se empurrou sua esposa durante a discussão (Sr. 43); que não se recorda muito dos fatos (Sr. 66).

Por outro lado, ao negar as acusações, se coloca como vítima da companheira: a vítima começou a bater no interrogado (Sr. 9); sua companheira the desferiu um tapa na nuca (Sr. 26); sem qualquer motivo agride e humilha o declarante (Sr. 32); a companheira começou a dar tapas nas costas do declarante em razão de ele ter chegado tarde (Sr. 71); nega as acusações que lhe são feitas, que a companheira é que lhe está perturbando o sossego ( Sr. 76).

Dessa forma justificam seus atos porque sofrem agressões no ambiente doméstico, todavia estudos encontraram que este tipo de violência 
contra o homem é desencadeado após algum ato de violência cometido pelo companheiro. Além disso, mesmo que alguns homens possam ser humilhados, desqualificados e agredidos física e verbalmente por uma mulher, é difícil imaginálos permanentemente aterrorizados ou devastados em sua autoestima ${ }^{11,32}$.

Os homens ainda relatam que as denúncias são infundadas e estruturam o depoimento desqualificando a companheira, de forma a fazer crer que as marcas da agressão são causadas por ela mesma, ou ainda tentando construir a imagem da mulher como inconsequente e débil ${ }^{11,13}$. A mulher é então desqualificada, por apresentar um comportamento não esperado, alguma doença ou característica que a torne não confiável: ressalta que a esposa possui problema psiquiátrico (Sr. 105); entende que sua esposa aumentou um pouco os fatos (Sr. 83); que a companheira alterava de comportamento constantemente e rapidamente, de forma imotivada (Sr. 85); uma hora ela tá de um jeito e de outra hora outro (Sr. 53).

Outro aspecto percebido nos depoimentos dos homens, é a relação que fazem entre a queixa da mulher a algum benefício financeiro, ou uma forma de prejudicar ou ameaçar o companheiro, o que foi percebido no estudo de Deek et al. ${ }^{11}$. Estes relatos ilustram essa categoria: acha que a companheira registrou o boletim de ocorrência por motivo de vingança (Sr. 36); efetuou o referido registro de ocorrência para poder chantagear o interrogado quanto a partilha dos bens (Sr. 63); que esta chamou a polícia porque o interrogado não quis dormir com ela (Sr. 135); quer prejudicar ele, pois ela não aceitou a separação (Sr. 114); que ela sempre procurou criar situações no sentido de se fazer passar por vítima e assim prejudicar o interrogado (Sr. 113).

\section{Considerações finais}

Apesar das políticas, projetos e programas para diminuição da violência doméstica contra a mulher, esta ainda apresenta números elevados e atinge mulheres em diferentes situações socioeconômicas. O estudo da violência entre parceiros íntimos, com a inclusão da ótica do homem e da mulher envolvidos permite, portanto, ampliar a discussão sobre os motivos e as características das agressões, fornecendo mais subsídios para o enfrentamento desta situação.

Foi possível perceber que mesmo após a separação os casais permanecem em situação de conflito, e embora algumas características tidas como comuns no perfil das mulheres e dos homens envolvidos em violência conjugal também percebidas neste estudo, o alto índice de desemprego não esteve presente na população investigada. Esta diferença pode indicar mudanças no perfil dos envolvidos ou na atitude destes, que passam a procurar a intervenção de órgãos responsáveis pela investigação destes atos, como as Delegacias de apoio à Mulher.

O uso de drogas, em especial o álcool, e as crises de ciúme aparecem como causa da violência tanto no depoimento das mulheres como dos homens, e evidenciam questões culturais e relacionadas às questões de gênero, que perpetuam a ideia de posse entre os parceiros.

A análise dos depoimentos evidenciou as diferentes percepções que o homem tem frente à situação em que foi acusado de perpetrar violência, indo da negação à culpabilização da mulher e sua desqualificação. Esse fato demonstra que alguns atos violentos não são percebidos como tal, o que aponta para a banalização da violência e a necessidade de investimentos nos aspectos culturais que discutam questões de gênero e desnaturalizem a violência doméstica contra a mulher. Homens relataram que sofrem violência perpetrada pela companheira, principalmente a verbal, o que aumentaria a tensão nos relacionamentos. Entretanto, o uso da violência física pelos homens contra as mulheres é sobremaneira mais grave e danoso à saúde física das mesmas e, consequentemente à sua saúde emocional e à vida social.

Devem-se levar em conta as peculiaridades dos relatos presentes nos inquéritos policiais e a situação em que estes são registrados, entretanto as delegacias ainda são consideradas porta de entrada para casais em situação de violência, e as informações obtidas a partir de sua atuação podem permitir conhecer aspectos relacionados a este tipo de violência.

A violência nas relações íntimas é um fenômeno complexo, culturalmente tolerado ainda em algumas sociedades como a brasileira. O olhar sobre a violência de gênero ainda está pautado na vitimização das mulheres, dificultando assim a ampliação do entendimento das relações violentas em todo o seu contexto, tanto a que é praticada pelo homem contra mulher como a praticada pela mulher contra o homem, dos homens contras homens e das mulheres contra mulheres. Este estudo limitou-se a compreender as relações entre homens e mulheres parceiros íntimos e procurou investigar as causas da violência a partir dos depoimentos desses parceiros. Pela ausência de políticas públicas que possam oferecer uma 
atenção à violência conjugal, que inclua homens e mulheres no atendimento, pelas poucas intervenções setoriais neste contexto, resta às delegacias o papel de punir e coibir essas agressões. Isso chama a atenção para o fundamental papel de outros setores como o da saúde, na transformação desses contextos e na redução de morbidade e mortalidade por violência que acometem homens e mulheres nas relações de intimidade.

\section{Colaboradores}

ACLG Silva, EBS Coelho e K Njaine participaram igualmente de todas as etapas de elaboração do artigo.

\section{Referências}

1. Córdova LFN, organizador. Os 25 anos da "Delegacia da Mulher" de Florianópolis: impasses e perspectivas para a 'base da pantera'. Florianópolis: UFSC, CFH, NUPPE; 2010.

2. World Health Organization (WHO). World report on violence and health. Geneva: WHO; 2002.

3. Gomes R. A dimensão simbólica da violência de gênero: uma discussão introdutória. Athenea Digit 2008; 14(2):237-243.

4. Giffin K. Violência de Gênero, Sexualidade e Saúde. Cad Saude Publica 1994; 10(1):146-155.

5. Schraiber, LB, D’Oliveira, AFPL, França Júnior, I, Pinho, AA. Violência contra a mulher: estudo em uma unidade de atenção primária à saúde. Rev Saude Publica 2002; 36(4):470-477.

6. Inter-American Development Bank (IDB). Violence as an Obstacle to Development. Technical Note 4. [Internet]. [acessado 2012 jun 8]. Disponível em: http://idbdocs.iadb.org

7. United Nations. Department of Economic and Social Affairs. The World's Women 2010: Trends and Statistics. New York: United Nations publication; 2010.

8. Instituto Avon. Percepções sobre a violência doméstica contra a mulher no Brasil. São Paulo: Instituto Avon; 2011.

9. Carrasco-Portiño M, Vives-Cases C, Gil-Gonzalez D, Alvarez-Dardet C. ¿Qué sabemos sobre los hombres que maltratan a su pareja? Una revisión sistemática. Rev Panam Salud Publica 2007; 22(1):55-63.

10. Castro R, Riquer RF. Research on violence against women in Latin America: from blind empiricism to theory without data. Cad Saude Publica 2003; 19(1): 135-146.

11. Deeke LP, Boing AF, Oliveira WF, Coelho EBS. A dinâmica da violência doméstica: uma análise a partir dos discursos da mulher agredida e de seu parceiro. Saúde Soc 2009; 18(2):248-258.

12. Frank S, Coelho EBS, Boing AF. Perfil dos estudos sobre violência contra a mulher por parceiro íntimo: 2003 a 2007. Rev Panam Salud Publica 2010; 27(5):376-381. 
13. Freitas L. Representações de Papeis de Gênero na violência Conjugal em Inquéritos Policiais. Cadernos de Linguagem e Sociedade 2011; 12(1):128-152.

14. Lamoglia CVA, Minayo MCS. Violência conjugal, um problema social e de saúde pública: estudo em uma delegacia do interior do Estado do Rio de Janeiro. Cien Saude Colet 2009; 14(2):595-604.

15. Bardin L. Análise de conteúdo. Lisboa: Edições 70; 1977.

16. Minayo MCS. O Desafio do Conhecimento: Pesquisa Qualitativa em Saúde. 6a ed. São Paulo, Rio de Janeiro: Hucitec, Abrasco; 1999.

17. Brasil. Ministério da Saúde (MS). Conselho Nacional de Saúde. Resolução no 196 de 10 de outubro de 1996. Diretrizes e Normas Regulamentadoras de Pesquisas Envolvendo Seres Humanos. Diário Oficial da União 1996; 16 out.

18. Garcia MV, Ribeiro LA, Jorge MT, Pereira GR, Resende AP. Caracterização dos casos de violência contra a mulher atendidos em três serviços na cidade de Uberlândia, Minas Gerais, Brasil. Cad Saude Publica 2008; 24(11):2551-2563.

19. Gupta J, Silverman JG, Hemenway D, AcevedoGarcia D, Stein DJ, Williams DR. Physical violence against intimate partners and related exposures to violence among South Africa men. Canadian Medical Association Journal 2008; 179(6):535-541.

20. Moura LBA, Gandolfi L, Vasconcelos AMN, Pratesi R. Violência contra mulheres por parceiro íntimo em área urbana economicamente vulnerável, Brasília, DF. Rev Saude Publica 2009; 43(6):944-953.

21. Oliveira JB, Lima MCP, Simão MO, Cavariani MB, Tucci AM, Kerr-Corrêa F. Violência entre parceiros íntimos e álcool: prevalência e fatores associados. Rev Panam Salud Publica 2009; 26(6):494-500.

22. Audi CAF, Segall-Corrêa AM, Santiago SM, Andrade MG, Pérez-Escamila R. Violence against pregnant women: prevalence and associated factors. Rev Saúde Pública 2008; 42(5):877-885.

23. Frye V, Latka MH, Valverde EE, Knowlton AR, Knight KR, Arnsten JH, O'Leary A. Intimate Partner Violence Perpetration Against Main Female Partners Among HIV-Positive Male Injection Drug Users. J AcquirImmuneDeficSyndr 2007; 46(2):101-109.

24. Wathen CN, Jamieson E, Wilson M, Daly M, WorsterA, MacMillan HL. Risk indicators to identify intimate partner violence in the emergency department. Open Medicine 2007; 1(2):113-122.

25. Pasinato W, Santos CM. Mapeamento das Delegacias da Mulher no Brasil. São Paulo: PAGU, UNICAMP; 2008.
26. Melo ZM, Silva DM, Caldas MT. Violência Intrafamiliar: crimes contra a mulher na área metropolitana do Recife. Psicologia em Estudo 2009; 14(1):111119.

27. Dalal K, Rahman F, Jansson B. Wife abuse in rural Bangladesh. J BiosocSci 2009; 41(5):561-573.

28. Aekplakorn W, Kongsakon R. Intimate Partner violence among women in slum communities in Bangkok, Thailand. Singapore Med J 2007; 48(8):763768.

29. Ntaganira J, Muula AS, Masaisa F, Dusabeyezu F, Siziya S, Rudatsikira E. Intimate partner violence among pregnant women in Rwanda. BMC Women's Health 2008; 8:17.

30. Dossi AP, Saliba O, Garbin CAS, Garbin AJI. Perfil epidemiológico da violência física intrafamiliar: agressões denunciadas em um município do estado de São Paulo, Brasil, entre 2001 e 2005. Cad Saude Publica 2008; 24(8):1939-1952.

31. Abrahams N, Jewkes R, Laubscher R, Hoffman M. Intimate Partner Violence: Prevalence and risk Factors for men in Cape Town, South Africa. Violence and Victims 2006; 21(2):247-264.

32. Alves SLB, Diniz NMF. "Eu digo não, ela diz sim": a violência conjugal no discurso masculino. Revista Brasileira de Enfermagem 2005; 58(4):387-392.

33. Couto MT, Schraiber LB, D'Oliveira AFPL, Kiss LB. Concepções de gênero entre homens e mulheres de baixa renda e escolaridade acerca da violência contra a mulher. Cien Saude Colet 2006, 11(Supl.): 1323-1332.

34. Acosta F, Barker G. Homens, violência de gênero e saúde sexual reprodutiva. Rio de Janeiro: Instituto Promundo; 2003.

35. Rosa AG, Boing AF, Büchele F, Oliveira WF. Coelho EBS. A violência Conjugal contra a mulher a partir da ótica do homem autor da Violência. Saúde Soc 2008; 17(3):152-160.

Artigo apresentado em 18/03/2013

Aprovado em 28/04/2013

Versão final apresentada em 19/05/2013 